\title{
Síndrome PFAPA - A propósito de um caso clínico nos Cuidados Primários
}

\author{
PFAPA Syndrome - About a clinical case in Primary Health Care
}

Síndrome PFAPA - A propósito de un caso clínico en los Cuidados Primarios

Beatriz Abreu Cruz $@$, Margarida Garrett Silva²®

1 USF Reynaldo dos Santos - Póvoa de Santa Iria, ACES Estuário do Tejo, ARS Lisboa e Vale do Tejo, Lisboa, Portugal.

2 USF Gago Coutinho - Alverca do Ribatejo, ACES Estuário do Tejo, ARS Lisboa e Vale do Tejo, Lisboa, Portugal.

Foi com interesse que lemos o trabalho de Bueno et al. sobre síndrome PFAPA ${ }^{1}$ publicado na Revista Brasileira de Medicina de Família e Comunidade em maio de 2019 (v. 14, n. 41), pois tratando-se de uma patologia descrita pela primeira vez há mais de 30 anos é ainda pouco conhecida pela comunidade médica e pouco discutida nos Cuidados de Saúde Primários (CSP).

A propósito deste artigo, descrevemos um caso recentemente observado na nossa prática clínica numa Unidade de Saúde Familiar da Grande Lisboa: sexo feminino, 6 anos, com história de febre recorrente desde os 21 meses, com intervalos intercrises de 15 dias a 3 meses, duração média de 7 dias, acompanhado de tonsilites, com culturas de secreção de orofaringe negativas, aftose recorrente e artralgias. A febre regride após administração de corticoide oral em D1 de doença e encontra-se assintomática nos períodos intercrise. Foi submetida à tonsilectomia em abril de 2019 e encontra-se assintomática desde então. Esta doente apresenta desenvolvimento psicomotor e estato-ponderal adequados. Excluíram-se outras síndromes autoinflamatórias. Não se registram antecedentes pessoais relevantes e como antecedentes familiares destaca-se mãe, avós maternos e avó paterna com história de tonsilites recorrentes e tonsilectomia.

Como citar: Cruz BA, Silva MG. Síndrome PFAPA - A propósito de um caso clínico nos Cuidados Primários. Rev Bras Med Fam Comunidade. 2019;14(41):2146. https://doi.org/10.5712/rbmfc14(41)2146
Autor correspondente: Beatriz Abreu Cruz. E-mail: beatrizcruz@campus.ul.pt Fonte de financiamento: declaram não haver. Parecer CEP: não se aplica. Procedência e revisão por pares: revisado por pares. Recebido em: 19/07/2019. Aprovado em: 19/07/2019. 
Descrevemos este caso para destacar a importância da sensibilização dos profissionais de saúde nos CSP para esta patologia, cujo diagnóstico é clínico e de exclusão. Trata-se de uma doença autolimitada com evolução benigna, mas que acarreta importante prejuízo da qualidade de vida dos doentes e familiares. Por outro lado, o seu diagnóstico adequado evita a exposição a tratamentos supérfluos, como antibioterapia, bem como aos riscos associados. Cabe ao Médico de Família reconhecer quando fazer a referenciação aos Cuidados de Saúde Especializados, quer para exclusão de outras patologias cuja investigação não possa ser realizada nos CSP quer para instituição de terapêutica que não se encontra ao seu alcance neste nível de cuidados, nomeadamente a tonsilectomia quando indicada. Para este efeito, é particularmente relevante o fluxograma apresentado pelos autores no artigo referido.

Trata-se de uma patologia que pode ser acompanhada nos CSP, não se excluindo a necessidade de uma adequada articulação com os cuidados hospitalares.

\section{Contribuição dos autores}

Concepção e/ou delineamento do caso clínico: BAC, MGS. Pesquisa e interpretação dos dados: BAC, MGS. Redação preliminar: BAC. Revisão crítica da versão preliminar: MGS. Todos os autores aprovaram a versão final e concordaram com prestar contas sobre todos os aspectos do trabalho.

\section{Conflito de interesses}

Declaram não haver.

\section{Referências}

1. Bueno LA, Paiva DM, de Carvalho PHP. Síndrome PFAPA: Diagnóstico e Tratamento na Atenção Primária à Saúde. Rev Bras Med Fam Comunidade [Internet]. 2019; [citada em 30 Mai 2019];14(41):1815. https://doi.org/10.5712/rbmfc14(41)1815 